\title{
Effect of Health Education Program on Knowledge and Practices about Menstrual Hygiene among Adolescents Girls at Orphanage Home
}

\author{
Reda Ibrahim El-Mowafy ${ }^{l}$, Maha Moussa Mohamed Moussa ${ }^{2}$ \\ and Hanan Hassan El-Ezaby ${ }^{3}$ \\ ${ }^{(1,2,3)}$ Lecturers, Department of Community Health Nursing , Faculty of Nursing , Port Said University, Port \\ Said, Egypt.
}

\begin{abstract}
:
Background: Menstruation is a natural phenomenon among matured females who experience shedding of blood for 1-7 days every month from the age of maturity until menopause. On the other hand, hygienerelated practices during menstruation are of considerable importance for reproductive health, poor practices increase vulnerability to reproductive tract Infections.

Aim: The present study aimed to improve level of knowledge and practices about menstrual hygiene among adolescents girls at Orphanage home.

Methodology: Research design: A quasi-experimental design was used to met aim of the study.

Setting: The study was conducted at seven Orphanage homes in Damietta City.

Sample: The total sample was 234 adolescents girls, aged $<14-\geq 16$ years. They were assigned to either study and control groups. The study data were collected by a structure interview questionnaire sheet in three months .

Results: The study revealed that there were highly statistically significant differences in total knowledge and practice score of the studied sample after implementation of educational program.

Conclusion: The present study concluded that adolescents lacked appropriate knowledge and practices about menstruation in the pre- program phase. After implementation of the program considerable improvements were noticed in adolescents girls' knowledge and practice. Therefore the educational program was successful in attaining its aims of positively changing the knowledge and practice of menstrual hygiene.
\end{abstract}

Recommendations: Development of in-service training program for health care providers who take care of adolescent girls at orphanage home about issues related to menstruation and reproductive health

Keywords: Menstruation, menses, menarche, adolescent and menstrual hygiene.

\section{Introduction:}

Adolescence is a significant period in the life of a female. Adolescent girls often lack knowledge regarding reproductive health including menstruation which can be due to socio-cultural barriers in which they grow up $(1,2)$. Menstruation is the normal and physiological process of the discharge of blood from the uterus which is unique to females that begins in adolescence $(3,4,5)$. The first menses is called "Menarche". Menarche is the signal that sexual maturation of the young female has occurred and that the body is capable of supporting pregnancy. With onset of menstruation a girl becomes aware of her emerging identity as a female capable to reproduce. Her understanding and acceptance of her new identity will be greatly influenced by the feedback she receives from peers, educators and most importantly her parents $(6,7)$. Menstruation occurs periodically throughout the child bearing years, except during pregnancy and lactation. The ages of onset of menstruation differ from person to person but seem to be affected by heredity, racial background and nutritional status $(8,9)$. Menstrual flow consists of blood, mucus, and tissue particles. Factors that may alter the menstrual cycle are stress, fatigue, exercises, acute (or) chronic illness, and changes in climate. Menstrual hygiene is the personal hygiene during menstruation. It includes bathing daily for comfort, using clean, dry absorbent material and disposal of used pads/material in clean environmentally acceptable , safe methods and to feel fresh, keep perieneal area clean from anterior to posterior, $(10,11)$.

Significance of the study: Majority of adolescent girls usually have lack of scientific knowledge and hygienic practice during menstruation and puberty, also Adolescent girls often are reluctant to discuss this embracing topic with their care-providers and often hesitate to seek help regarding the menstrual problem from external sources. So, girls should be educated about "menstruation and healthy menstrual 
practices" through expanded programe of health education in orphanage homes. Data on their level of knowledge and practices are beneficial for planning programe for improving their awareness level.

\begin{abstract}
Aims of the study:
The aim of this study was to improve level of knowledge and practices about menstrual hygiene among adolescent girls at orphanage home through:

1- Assessing the level of knowledge and practice regarding menstrual hygiene among study sample.

2- Planning, implementing and evaluating the effect of health education program about menstrual hygiene among study sample.
\end{abstract}

\title{
Subjects and Methods \\ Research Design:
}

A quasi-experimental design was used to met aim of the study.

\section{Setting:}

This study was carried out at seven orphanage homes in Damietta City namely (Fareskour 38 girls, EL-Zarqa 26 girls, Kafr Sad 40 girls, Damietta 52 girls, EL-Sru 30 girls, Ras El Bar 32 girls and New Damietta 16 girls).

\section{Sample:}

The subjects consisted of all adolescents girls in the aforementioned orphanage homes in Damietta City. The total sample was 234 girl, aged $<14-\geq 16$ years. They were assigned to either study and control groups in each home previously mentioned. The subjects were divided randomly into 2 groups: 117 adolescents girls as study group who were received the educational program and the other 117 adolescents girls as control group who didn't received any program.

\section{Tools of Data Collection:}

Data was collected by three tools, these tools was developed the researchers based on the review of related literature.

Tool I - A Structured Interview questionnaire Sheet: This tool divided into 2 parts; part (1): related to socio-demographical data of the studied sample, including age, birth older and residence. Part (2): related to history of menstruation including; age of menarche, regular of menses, abnormality, density , duration and interval of each menses. Tool II - Adolescent's knowledge about menses such as culture, girls experience, definition, causes, manifestations, factors effect of menses, treatment and complications. Tool III - Self care practices including water sanitation, hygienic care (Perieneal hygiene, underwear, methods of cleaning, shaving the hair in genital area, drink, food restrictions, exercise and treatment). Also, type of pads used, number of pads per day, wash clothes of menses, waste dispose of pad and methods of drying.

\section{Health Educational Program:}

An educational intervention program was developed in a simple Arabic language.

\section{The aim of the program:}

The program aimed to improve level of knowledge and practices about menstrual hygiene among adolescent girls at orphanage home. An educational program to study group included: knowledge about menstruation as; definition, causes, clinical manifestations, complications and treatment. Also the practices related to self care of menstruation as; diet, drink, exercise, perieneal care, hygienic care, types of pads, waste dispose of pad, wash of clothes and methods of drying of clothes.

\section{Field work:}

The study was conducted through four phases: Pre-planning, planning, implementation, and evaluation. Phase1 (Pre-planning): before starting-up program design the study tools and were applied it to assess adolescent girls knowledge and practices about menstrual hygiene. Phase11(program planning): the program was developed based on the identified needs and demands of adolescent girls. Phase111(program implementation): An educational program was implemented to study group of adolescent girls in each home. Each group obtained 2 sessions, each session took about one hour. Each group was attended according to their available times and place, which commonly in the morning between $10.00 \mathrm{AM}$ until $12.00 \mathrm{AM} .1^{\text {st }}$ session included pretest and information about definition, causes, signs and symptoms, complications and treatment of menstruation, $2^{\text {nd }}$ session included practices regarding diet, exercise and personal hygiene and perieneal care. At the end of each session the researchers ensured the adolescents understanding of the 
instructions. The program was presented in clear and concise form and focused on the point of learning using different teaching methods, as illustrative lecture, group discussion, role playing, demonstration, and re -demonstration were used. Also different audio visual materials were used as pamphlets, hand out, pictures, and posters to facilitate the teaching of each topic. After program Implementation a post-test was done immediately to measure its effect on the knowledge and practices about menstrual hygiene among study sample.

\section{Method:}

The questionnaire sheet was developed by the researchers after reviewing the related literature. Tools were tested for content validity by 3 experts in the field and they were structured interview questionnaire sheet. A pilot study was carried out on $10 \%$ of the adolescents, to test the feasibility of different and help in time planning. Necessary modifications were done. They were excluded from the subjects of the study. Oral consent from each adolescent girl of both the study and control groups was obtained for their participation in the study after explaining the aim of the study and assured that all the collected data were confidential and will be used only for the purpose of the study. Each adolescent was individually interviewed to assess her knowledge and practices about menstruation educational program was developed based on the adolescents' assessment The interview lasted for an average of 15 minutes. The data were collected from orphanage home, started from the $1^{\text {st }}$ October 2012 and extended to 30 March 2013. This period consumed for data collection was governed by the availability time for both the researchers and the study respondents.

\section{Statistical design}

The collected data in pretest and post test were organized, categorized, tabulated according to the type of each data

\section{Statistical analysis:}

The Statistical Package for the Social Sciences (SPSS, version 17.0) was used for data analysis. Descriptive statistics were employed to summarize the demographic data, which was presented using frequency tables and expressed as percentages, mean and standard deviation. Chi-square test was used to test the associations among the under studied qualitative variables. Statistical significance was considered at Pvalue $<0.05$ and highly significance at $\mathrm{P}$-value $<0.001$.

\section{Scoring system:}

Scores were used to evaluate participant's knowledge of hygienic and healthy practices during menstruation. Questions were scored as followed 1 marks for correct answer and 0 marks for wrong or no answer. The total score of each aspect equal $60 \%$ or more than $\rightarrow$ adequate or satisfactory knowledge and practice) The total of each aspect less than $60 \% \rightarrow$ inadequate e or unsatisfactory knowledge and practice.

\section{Results:}

Table (1) Shows the demographic characteristics among study and control groups. Regarding age, it can be seen that the higher percentage $(41.9 \%, 34.2 .1 \%)$ respectively their age ranged from $<14$ to $\geq 16 y e a r s$. As regarding the older birth, the table shows that slightly more than half $(50.4 \%, 41.9 \%)$ respectively among study and control groups between $2-5+$. The two groups were almost equally distributed of residence in rural.

Table (2) Illustrates Comparison between the study and control groups according to Menstrual pattern, it was noticed that there was no statistically significant changes could be detected after program implementation in either of the two groups, $p>0.05$ regardless the age of menarche, regular of menses, abnormal density of menses, duration and interval of each of menses.

Table (3) Show that there was a highly statistically significant for improvement in knowledge about definition of menses, dysmenorrheal, poly-menorrhea, time of ovulation, signs and symptoms before or during menses, causes of pain or discomfort, factors effecting of menses, methods of treatment and complications when compared to values before program. Data shows also statistically significant differences within the study and control group.

Table (4) It can clearly be seen that, there was a highly significance difference in all items related to comprehensive care for menses, table reflect good prognosis of acquired prevented practice care in pre educational program comparing to post program of the study group. 
The changes in practical knowledge observed after program implementation are illustrated in table (5) shows that there were statistically significant differences in the implementation group before and after the program of study group with $\mathrm{p}$-value $<0.001$, but not in the control group, $\mathrm{p}>0.05$ regarding practical knowledge in all items.

Figure ( 1 ) Illustrate the distribution of the study group according to their sources of information it was found that they get information about menstrual hygiene primarily from their friends, relatives and health team at home as reported by $(25.6 \%, 15.5 \% \& 9.5 \%)$ of them respectively. On other hand the control group it was found that their friends, relatives and health team at home as reported by $(23.1 \%, 15.5 \% \& 9.5 \% \%)$ of them respectively. Therefore undoubtedly poverty and play a major role on the choices of absorbents leading to the use of unsanitary materials. It is likely that a poor financial resource has contributed to the use of 'multiple material' as menstrual absorbents.

\section{Discussion:}

The aim of the present was to improve level of knowledge and practices about menstrual hygiene among adolescent girls at orphanage home in Damietta. Adolescence is a time of enormous physical and hormonal change for a young girl although organic gynecological pathologies are rare in this period, menstrual disorders may be seen commonly, and may cause further problems for the adolescents and their parents. The two groups were randomly selected and compared as regards the demographic data such as age, older birth and residence. The age of menarche is determined by general health, genetic factors, socioeconomic and nutritional status. From the present study findings, more than half of the study sample , in the study group that their age at menarche ranged from 9 to 12 years and the girls were well prepared and aware about menarche. These findings supported by $(12,13,14)$ who mentioned that mostly sixty seven percent of the girls were well prepared and aware about menarche .Also, Supportive evidence by $(6,15)$ reported that the mean age at menarche among Egyptian female adolescents was $12.87 \pm 1.29$ years. In a study in Mansoura, Egypt 2004, the mean age at menarche was 12.9 years. While in Alexandria 2004, the mean age was $11.91+0.93$ years .In a study Jordanian girls 2004 among the mean age was 13.8 years. This difference could be attributed to the influence of both heredity and socioeconomic conditions especially nutrition $(6,17,18,19)$. The present study showed that two thirds of the study and more one third of the rural and urban participants respectively had awareness about menstruation prior to menarche after the program. Similarly, a qualitative study carried out in rural Kenya showed that shame were the feelings of girls associated with menstruation(20,21).

As regards the main source of information, the findings of the present study have shown that the. girls had a fairly good understanding on the topic of menstruation the girls reported friends and relatives identified they were the source of information and whom they discussed menstruation issues with. Information was often shared before menarche or after they had started their periods. This may be attributed to lack of friend's time to give girls a good model of practices which affect her behavior. Maximum number of the girls had previous knowledge regarding menstrual hygiene and the major source of their information was health personnel in the study conducted by $(22,23,24)$ mention that the health personnel were the majority main source of information this portrayed that relatives, teachers, ....etc are not sufficiently providing the knowledge regarding menstrual hygiene to the girls. Thus, there is the need to educate the relatives and teachers regarding menstrual hygiene and motivate them to educate the adolescent girls. $(8,25)$.

Students knowledge about definition such as menstruation was similar in its deficiency among the two groups before the implementation of the program. This deficiency Signs and symptoms before or during menses This finding is supported by the study conducted by $(26,27,28)$ which depicted that less one third of the girls had good knowledge about menstrual hygiene, more than half had fair knowledge and of them had poor knowledge on menstrual hygiene mean was 21.67. Dysmenorrhea which manifested as abdominal pain, back pain and headaches, was the most common medical problem among the girls in this study. A similar finding was observed by $(29,30,31)$ who indicated that the study on knowledge assessment regarding puberty and menstruation among adolescent school girls in Varanasi district, India. Again by $(32,33,34)$ observed a poor perception and behavior towards the use of sanitary pads during menstruation among adolescent school going girls which is similar to the result of this study, as they noted that lack of finance was responsible for non-usage of sanitary pads and hence the use of ether absorbent such as clothes. This was consistent with other studies carried out among the same population in developing countries (35,36,37,38). Girls said that the pain was unbearable and they could not eve concentrate in class. Majority of the girls reported that they did not use any pain killers due to the cost of modern medicine and if they did, some used traditional healers. The participants mentioned that they mostly purchased the sanitary pads when they had money, or when the mother was financially able to 
purchase them, otherwise pieces of cloth were used. One participant shared that her sister bought them for her, but wanted her to use them only when she was going to special places.

\section{Conclusion}

In the light of the study findings, it can be concluded that adolescent's girls lacked appropriate knowledge about menstruation and menstrual hygiene in the pre-program phase. Also adolescents' lifestyle practices were mostly inadequate as regards exercise, sleeping, diet, drinks, medication, pain management, personal hygiene and washing of clothes. After implementation of the program considerable improvements were noticed in adolescents knowledge and practice. Therefore the educational program was successful in attaining its aims of positively changing the knowledge and practice of menstruation.

\section{Recommendation}

The findings from this study made the researchers to make the following recommendation:

- It is important to educate adolescents about issues related to menstruation, so that they can safeguard themselves against various infections and diseases. Further, emphasis also needs to be given through workshops, school classes and seminars on "Adolescent Reproductive Health".

-Development of in-service training programs for health care providers who take care of adolescent girls at orphanage home about issues related to menstruation and reproductive health.

-Any Maternal and Child Health Centers( $\mathrm{MCH})$ or health setting should provide health teaching for adolescent Community campaigns using various educational media are essential to increase knowledge and awareness about menstruation among all girls or adolescents in orders to identify the menstruation and the self care practices or appropriate management.

\section{Competing interests}

The authors declare that they have no competing interests.

Authors' contributions

Reda El-Mowafy conceived the study idea, designed the review methodology, conducted the critical appraisal of the studies and drafted the manuscript. Maha Moussa collect data, wrote the first draft of the manuscript, revision of the manuscript for important intellectual content and approved the submitted draft. Hanan El-Ezaby designed the program Analysis and interpretation of data critical, The final version of the manuscript was critically reviewed by all authors read and approved the final manuscript.

\section{Acknowledgement}

First of all, I would like to express my endless and deepest thanks to "God" for his magnificent help, which enables me to accomplish this work. I wish to convey my gratitude to all personnel , care providers, with particular recognition to the adolescents in the study. We hope this study will serve the purpose of informing the strategies and actions for any concerned population in improving the menstrual hygiene and management particularly in adolescent school girls.

\section{References}

[1]. Dhingra R, Kumar, A; and KourM. Knowledge and Practices Related to Menstruation among Tribal (Gujjar) Adolescent Girls. Ethno-Med.2009; 3(1): 43-48.

[2]. Diaz A, Laufer R, Breech L. Menstruation in girls and adolescents: using the menstrual cycle as a vital sign. Pediatrics. 2006 ; $118: 2245-2250$

[3]. Begum J, Hossain AM and Nazneen SA. Menstrual Pattern and Common Menstrual Disorders among Students in Dinajpur Medical College . Dinajpur Med Col J.2009; 2 (2):37-43.

[4]. Deo DS, Ghattargi $\mathrm{CH}$. Perceptions and practices regarding menstruation: a comparative study in urban and rural adolescent girls Indian J Community Med 2005;30:33-4.

[5]. Aniebue UU, Aniebu PN, Nwankwo TO . The impact of pre- menarcheal training on menstrual practices and hygiene of Nigerian school girls. Pan African Medical Journal. 2009: 2(9), 27-36.

[6]. Ei-Gilanya A, Badawi K, El- Fedawy S. Menstrual hygiene among adolescent school girls in Mansoura, Egypt. Reprod. Health Matters.2005; 13(26):147-152.

[7]. Karout N, Hawai SM and Altuwaijri S. Prevalence and pattern of menstrual disorders among Lebanese nursing students. Eastern Mediterranean Health Journal EMHJ. 2012;18(4) 346-352.

[8]. Bayray,A. Menstrual Perceptions and Preparation of Rural Adolescent Females in Tigray, North Ethiopia. Universal Journal of Education and General Studies. 2012; 1(1) pp. 009-016.

[9]. Adinma ED. Perceptions and practices on menstruation amongst Nigerian secondary school girls. Afri $\mathrm{J}$ of Reprod Health.2008; 12(1):74-83.

[10]. Eswi, A; Helal, Hand Elarousy, W. Menstrual Attitude and Knowledge among Egyptian Female Adolescents Journal of American Science. 2012; 8(6). 
[11]. Zegeye D. Age at menarche and the menstrual pattern of secondary school adolescents in northwest Ethiopia. BMC Women's Health.2009; 9: 29.

[12]. Myoung-Hee K and In-YoungY . Knowledge of Menstruation, Emotional Reaction to Menarche, Attitude toward Menstruation and Coping Behavior among Korean Primary School Students Korean J Women Health Nurs.2009; 15 (1): 64-72

[13]. Khudair F. Assessment the Level of awareness of Female Students toward menstruation in Nursing College Kufa Journal For Nursing . 2013; 3 (1): 57-62.

[14]. Sherestha S, Jaita M, Rajaina T. Knowledge attitude and practices towards menstrual hygiene among adolescent girls. International Journal of nursing education, 2013; 5(11), 221-27.

[15]. Sule T, Ukwenya E. Menstrual experiences of adolescents in a secondary school. TurkishGerman Gynecol Assoc. 2007; 8:714 .

[16]. Jarrah SS, Kamel AA. Attitudes and practices of school-aged girl towards menstruation. Int J Nurs Prac. 2012; 18:308-15.

[17]. Lee LK, Chen PC, Lee KK, Kaur J. Menstruation among adolescent girls in Malaysia a cross-sectional school survey. Singapore Med J. 2006;47(10):869-74.

[18]. Nemade I, Anjenaya S, Gujar R. Impact of health education on the knowledge and practices about menstruation among the adolescent girls of Kalamboli, Navi Mumbai. Health and Population: Perspective Issues.2009; 32(4):67-75.

[19]. Sommer M. Where the education system and women's bodies collide:The social and health impact of girls' experiences of menstruation and schooling in Tanzania. J Adolesc. 2010;33(4): 521-9.

[20]. Dipali N, Seema A. Impact of health education on knowledge and practices about menstruation among adolescent school girls of Kalamboli, Navi- Mumbai. Health and Population: Perspectives and Issues 2010; 32(4) 175-167.

[21]. Shokry E, Allah A, Elsayed E, Elsabagh M. Impact of Health Education Intervention on Knowledge and practice about Menstruation among Female Secondary School Students in Zagazig City. J Am Sci. 2011;7(9):737-47.

[22]. 22.Sudenshana R, Dasgupta A. Determinants of menstrual hygiene among adolescent girls: A multivariate analysis. Natl J Community Med. 2012;3(2):294-301.

[23]. Lena A, Nair N. Effectiveness of Reproductive Health Education among Rural Adolescent Girls: A school based intervention study in Udupi Taluk, Karnataka. Indian Journal of Medical Sciences 2008; 62 (11): 439-443.

[24]. Mudey AB, Keshwani N, Mudey GA, Goyal RC. A cross-sectional study on the awareness regarding safe and hygienic practices amongst school going adolescent girls in the rural areas of Wardha district. Global Journal of Health Science, 2010; 2(2):225-231.

[25]. Patil SN, Wasnik V and Wadke R. Health problems amongst adolescent girls in the rural areas of the Ratnagiri District of Maharashtra. Journal of Clinical and Diagnostic Research2009; 3(8):1784-90.

[26]. Joshi B.et al, Reproductive and health problems and health seeking behaviour among the adolescents in urban India. Indian Journal of Pediatrics2006; 73:509-13.

[27]. Ali TS, Rizvi NS. Menstrual knowledge and practices of female adolescents in urban Karachi, Pakistan. J. Adolesc. 2010;33(4):531-541.

[28]. Singh AJ. Place of menstruation in the reproductive lives of women in rural North India. Indian J Community Med. 2006;31(1):10-4.

[29]. Dasgupta A, Sarkar M. Menstrual Hygiene. Indian J Community Med. 2008;33(2):77-80.

[30]. Bang RA, Bang AT, Reddy MH Deshmukh MD, Baitule SB, Filippi V. Maternal morbidity during labor and the puerperium in rural homes and the need for medical attention: a prospective observational study in Gadchiroli, India. Int J Obstetr Gynaecol, 2004;111:231-8.

[31]. Ray S, Dasgupta A . Determinants of Menstrual Hygiene among Adolescent Girls: A multivariate analysis. Natl. J. Commun. Med.2012; 3(2):294-301.

[32]. El-LassyBR and MadianAA (2013). Impact of Health Education Program on Menstrual Beliefs and Practices of Adolescent Egyptian Girls at Secondary Technical Nursing School.Life Sci.; 10(2):335-345

[33]. Yonkers KA, O'Brein PMS, Eriksson E. Premenstrual syndrome Lancet, 2008;371:1200-1210

[34]. Hickey M, Balen A. Menstrual disorders in adolescence: Investigation and management. Hum. Reprod. Update .2003; 9: 493-504;

[35]. Ersoy B, Balkan C, Gunay T, Onag A Egemen A. Effects of different socioeconomic conditions on menarche in Turkish female students. Early Hum. Dev.2004; 76:115-25

[36]. Hassanen RH, Tosson MM, Abd El-Elkareem HE. Effect of health education and training program for secondary school students on menstruation at Assiut Governorate. Bulletin of High Institute of Public Health. 2004; $34(3)$ : 575 -94.

[37]. Palep-Singh M, Prentice A. Epidemiology of abnormal uterine bleeding. Best Practice \& Research. Clinical Obstetrics \& Gynaecology, 2007; 21:887-890.

[38]. Harlow SD, Campbell OMR. Menstrual dysfunction: a missed opportunity for improving reproductive health in developing countries. Reproductive Health Matters. 2000; 8: 142-146.

Table (1): Distribution of female in the study and control groups according to demographic data

\begin{tabular}{|c|c|c|c|c|c|c|}
\hline & \multicolumn{2}{|c|}{ Study group(n=117) } & \multicolumn{2}{|c|}{ Control group(n=117) } & \multicolumn{2}{|c|}{ Total $(n=234)$} \\
\hline & No. & $\%$ & No. & $\%$ & No. & $\%$ \\
\hline $\begin{array}{l}\text { Age(years) } \\
<14 \\
14- \\
\geq 16 \\
\end{array}$ & $\begin{array}{l}49 \\
40 \\
28 \\
\end{array}$ & $\begin{array}{l}41.9 \\
34.2 \\
23.9 \\
\end{array}$ & $\begin{array}{l}38 \\
39 \\
40 \\
\end{array}$ & $\begin{array}{l}32.5 \\
33.3 \\
34.2 \\
\end{array}$ & $\begin{array}{l}87 \\
79 \\
68 \\
\end{array}$ & $\begin{array}{l}37.2 \\
33.8 \\
29.1 \\
\end{array}$ \\
\hline $\begin{array}{l}\text { Birth older:- } \\
1^{\text {st }} \\
2-4 \\
5+ \\
\end{array}$ & $\begin{array}{l}19 \\
59 \\
39 \\
\end{array}$ & $\begin{array}{l}16.2 \\
50.4 \\
33.3 \\
\end{array}$ & $\begin{array}{l}23 \\
45 \\
49 \\
\end{array}$ & $\begin{array}{l}19.7 \\
38.5 \\
41.9 \\
\end{array}$ & $\begin{array}{c}42 \\
104 \\
88 \\
\end{array}$ & $\begin{array}{l}17.9 \\
44.4 \\
37.6 \\
\end{array}$ \\
\hline $\begin{array}{l}\text { Residence :- } \\
\text { Urban } \\
\text { Rural }\end{array}$ & $\begin{array}{l}41 \\
76\end{array}$ & $\begin{array}{l}35 \\
65\end{array}$ & $\begin{array}{l}38 \\
79\end{array}$ & $\begin{array}{l}32.5 \\
67.5\end{array}$ & $\begin{array}{c}79 \\
155\end{array}$ & $\begin{array}{l}33.8 \\
66.2\end{array}$ \\
\hline
\end{tabular}


Table (2): Comparison between the study and control groups according to Menstrual pattern

\begin{tabular}{|l|c|c|c|c|c||}
\hline \multirow{2}{*}{} & \multicolumn{2}{|c|}{ Study group } & \multicolumn{2}{c|}{ Control group } & \multirow{2}{*}{ P } \\
\cline { 2 - 5 } & No. & \% & No. & \% & \\
\hline Age of menarche:- & & & & & \\
$<9$ & 23 & 19.7 & 18 & 15.4 & \\
12 & 79 & 67.5 & 89 & 76.1 & $>0.05$ \\
$15+$ & 15 & 12.8 & 10 & 8.5 & \\
\hline Regular of menses & & & & & \\
Yes & 32 & 27.4 & 31 & 26.5 & $>0.05$ \\
No & 85 & 72.6 & 86 & 73.5 & \\
\hline Abnormal density of menses: & & & & & \\
Yes & 44 & 37.6 & 43 & 36.8 & $>0.05$ \\
No & 73 & 62.4 & 74 & 63.2 & \\
\hline Duration of menses : & & & & & \\
$<3$ day & 18 & 15.4 & 17 & 14.5 & \\
3-6 day & 82 & 70.1 & 84 & 71.8 & $>0.05$ \\
$\geq 7$ day & 17 & 14.5 & 16 & 13.7 & \\
\hline Interval of each menses: & & & & & \\
$<21$ day & 17 & 14.5 & 12 & 10.3 & \multirow{2}{*||}{} \\
21 day & 85 & 72.6 & 92 & 78.6 & 0.408 \\
$\geq 28$ day & 15 & 12.8 & 13 & 11.1 & \\
\hline
\end{tabular}

$\mathrm{p}$ : $\mathrm{p}$ value for comparing between pre and post program

*: Statistically significant at $\mathrm{p} \leq 0.05$

Table (3): Distribution of female in the study and control groups according to the knowledge about menses

\begin{tabular}{|c|c|c|c|c|c|c|c|c|c|c|}
\hline \multirow{3}{*}{ Items } & \multicolumn{4}{|c|}{ Study group } & \multicolumn{5}{|c|}{ Control group } & \multirow{3}{*}{$\begin{array}{c}\text { P- } \\
\text { Value }\end{array}$} \\
\hline & \multicolumn{2}{|c|}{ Pre program } & \multicolumn{2}{|c|}{ Post program } & \multirow{2}{*}{$\begin{array}{c}\mathrm{P}- \\
\text { value }\end{array}$} & \multicolumn{2}{|c|}{ Pre program } & \multicolumn{2}{|c|}{ Post program } & \\
\hline & No. & $\%$ & No. & $\%$ & & No & $\%$ & No & $\%$ & \\
\hline Definition of menses & 16 & 13.7 & 112 & 95.7 & $<0.001^{*}$ & 12 & 10.3 & 15 & 12.8 & $>0.05$ \\
\hline Definition of dysmenorrheal & 18 & 15.4 & 111 & 94.9 & $<0.001^{*}$ & 10 & 8.5 & 21 & 17.9 & $>0.05$ \\
\hline Definition of menstrual disorder & 18 & 15.4 & 109 & 93.2 & $<0.001^{*}$ & 19 & 16.2 & 29 & 24.8 & $>0.05$ \\
\hline Time of ovulation & 12 & 10.3 & 105 & 89.7 & $<0.001^{*}$ & 20 & 17.1 & 22 & 18.8 & $>0.05$ \\
\hline $\begin{array}{l}\text { Signs and symptoms before or } \\
\text { during menses }\end{array}$ & 15 & 12.8 & 107 & 91.5 & $<0.001^{*}$ & 22 & 18.8 & 25 & 21.4 & $>0.05$ \\
\hline Causes of increase bleeding & 17 & 14.5 & 108 & 92.3 & $<0.001^{*}$ & 32 & 27.4 & 35 & 29.9 & $>0.05$ \\
\hline Causes of pain or discomfort & 20 & 17.1 & 112 & 95.7 & $<0.001^{*}$ & 18 & 15.4 & 21 & 17.9 & $>0.05$ \\
\hline Factors effecting of menses & 17 & 14.5 & 115 & 98.3 & $<0.001^{*}$ & 17 & 14.5 & 22 & 18.8 & $>0.05$ \\
\hline Methods of treatment & 19 & 16.2 & 110 & 94 & $<0.001^{*}$ & 21 & 17.9 & 25 & 21.4 & $>0.05$ \\
\hline Complications & 14 & 12 & 114 & 97.4 & $<0.001^{*}$ & 12 & 10.3 & 20 & 17.1 & $>0.05$ \\
\hline
\end{tabular}

p: $p$ value for comparing between pre and post program

*: Statistically significant at $\mathrm{p} \leq 0.05$

Table (4): Self care practices during menstruation in study and control groups

\begin{tabular}{|c|c|c|c|c|c|c|c|c|c|c|}
\hline \multirow{3}{*}{ Items } & \multicolumn{4}{|c|}{$\overline{\text { Study group }}$} & \multicolumn{5}{|c|}{ Control group } & \multirow{3}{*}{$\begin{array}{c}\text { P- } \\
\text { Value }\end{array}$} \\
\hline & \multicolumn{2}{|c|}{ Pre program } & \multicolumn{2}{|c|}{ Post program } & \multirow{2}{*}{$\begin{array}{c}P \text { - } \\
\text { value }\end{array}$} & \multicolumn{2}{|c|}{ Post program } & \multicolumn{2}{|c|}{ Pre program } & \\
\hline & No. & $\%$ & No. & $\%$ & & No. & $\%$ & No. & $\%$ & \\
\hline Perineal hygiene & 17 & 14.5 & 117 & 100 & $<0.001^{*}$ & 29 & 24.8 & 33 & 28.2 & $>0.05$ \\
\hline $\begin{array}{l}\text { Underwear \& methods of } \\
\text { cleaning }\end{array}$ & 22 & 18.8 & 116 & 99.1 & $<0.001^{*}$ & 29 & 24.8 & 30 & 25.6 & $>0.05$ \\
\hline $\begin{array}{l}\text { Methods of shaving the hair in } \\
\text { genital area }\end{array}$ & 29 & 24.8 & 115 & 98.3 & $<0.001^{*}$ & 22 & 18.8 & 22 & 18.8 & $>0.05$ \\
\hline Frequency of change & 33 & 28.2 & 114 & 97.4 & $<0.001^{*}$ & 28 & 23.9 & 30 & 25.6 & $>0.05$ \\
\hline Exercise during menses & 12 & 10.3 & 111 & 94.9 & $<0.001^{*}$ & 18 & 15.4 & 20 & 17.1 & $>0.05$ \\
\hline $\begin{array}{l}\text { Herbal use / Traditional } \\
\text { methods }\end{array}$ & 15 & 12.8 & 110 & 94 & $<0.001^{*}$ & 14 & 12 & 16 & 13.7 & $>0.05$ \\
\hline Fluid intake & 22 & 18.8 & 109 & 93.2 & $<0.001^{*}$ & 25 & 21.4 & 28 & 23.9 & $>0.05$ \\
\hline
\end{tabular}


Effect of Health Education Program on Knowledge and Practices about Menstrual ....

\begin{tabular}{|l|c|c|c|c|c|c|c|c|c|c||}
\hline Food intake & 10 & 8.5 & 107 & 91.5 & $<0.001^{*}$ & 15 & 12.8 & 18 & 15.4 & $>0.05$ \\
\hline Medication & 66 & 56.4 & 4 & 3.4 & $<0.001^{*}$ & 69 & 59 & 69 & 59 & $>0.05$ \\
\hline $\begin{array}{l}\text { Absenteeism / and stay of home } \\
\text { during menses }\end{array}$ & 99 & 84.6 & 12 & 10.3 & $<0.001^{*}$ & 100 & 85.5 & 100 & 85.5 & $>0.05$ \\
\hline
\end{tabular}

$\mathrm{p}$ : $\mathrm{p}$ value for comparing between pre and post program

*: Statistically significant at $\mathrm{p} \leq 0.05$

Table (5) cont. Distribution of female in the study and control groups according to the self care practices of menses

\begin{tabular}{|c|c|c|c|c|c|c|c|c|c|c|}
\hline \multirow{3}{*}{ Items } & \multicolumn{4}{|c|}{ Study group $(n=117)$} & \multirow{3}{*}{$\begin{array}{c}\mathrm{p} . \\
\text { value }\end{array}$} & \multicolumn{4}{|c|}{ Control group $(n=117)$} & \multirow{3}{*}{$\begin{array}{c}\mathrm{p}- \\
\text { value }\end{array}$} \\
\hline & \multicolumn{2}{|c|}{ Pre-program } & \multicolumn{2}{|c|}{ Post program } & & \multicolumn{2}{|c|}{ Pre-program } & \multicolumn{2}{|c|}{ Post program } & \\
\hline & No & $\%$ & No & $\%$ & & No & $\%$ & No & $\%$ & \\
\hline $\begin{array}{l}\text { Type of pads used:- } \\
\text { Piece of old clothes } \\
\text { Piece of new clothes } \\
\text { Piece of cotton } \\
\text { Sanitary pad } \\
\end{array}$ & $\begin{array}{l}72 \\
23 \\
36 \\
66\end{array}$ & $\begin{array}{l}61.5 \\
19.7 \\
30.8 \\
56.4\end{array}$ & $\begin{array}{c}2 \\
115 \\
1 \\
116\end{array}$ & $\begin{array}{c}1.7 \\
98.3 \\
0.9 \\
99.1\end{array}$ & $<0.001^{*}$ & $\begin{array}{c}71 \\
3 \\
32 \\
49\end{array}$ & $\begin{array}{c}60.7 \\
2.6 \\
27.4 \\
41.9\end{array}$ & $\begin{array}{c}73 \\
4 \\
34 \\
49\end{array}$ & $\begin{array}{c}62.4 \\
3.4 \\
29.1 \\
41.9\end{array}$ & $>0.05$ \\
\hline $\begin{array}{l}\text { Number of pads per day } \\
\text { Single per day } \\
\text { Twice per day } \\
\text { Three per day } \\
\text { Four or more per day } \\
\end{array}$ & $\begin{array}{c}17 \\
77 \\
20 \\
3\end{array}$ & $\begin{array}{l}14.5 \\
65.8 \\
17.1 \\
2.6\end{array}$ & $\begin{array}{c}0 \\
1 \\
2 \\
114 \\
\end{array}$ & $\begin{array}{c}0 \\
0.9 \\
1.7 \\
97.4 \\
\end{array}$ & $<0.001^{*}$ & $\begin{array}{c}51 \\
40 \\
21 \\
5\end{array}$ & $\begin{array}{c}43.9 \\
34.2 \\
17.9 \\
4.3\end{array}$ & $\begin{array}{c}49 \\
42 \\
21 \\
5 \\
\end{array}$ & $\begin{array}{c}41.9 \\
35.9 \\
17.9 \\
4.3 \\
\end{array}$ & $>0.05$ \\
\hline $\begin{array}{l}\text { Wash clothes of menses: } \\
\text { With another of clothes } \\
\text { Wash clothes alone }\end{array}$ & $\begin{array}{l}56 \\
61 \\
\end{array}$ & $\begin{array}{l}47.9 \\
52.1 \\
\end{array}$ & $\begin{array}{c}1 \\
116 \\
\end{array}$ & $\begin{array}{c}0.9 \\
99.1 \\
\end{array}$ & $<0.001^{*}$ & $\begin{array}{l}55 \\
62 \\
\end{array}$ & $\begin{array}{l}47 \\
53 \\
\end{array}$ & $\begin{array}{l}54 \\
63 \\
\end{array}$ & $\begin{array}{l}46.2 \\
53.8 \\
\end{array}$ & $>0.05$ \\
\hline $\begin{array}{l}\text { Washing clothes:- } \\
\text { Pond water with soap } \\
\text { Pond water only } \\
\text { Tap water with soap } \\
\text { Tap water only } \\
\text { Tap water with antiseptic } \\
\end{array}$ & $\begin{array}{l}33 \\
22 \\
22 \\
17 \\
33 \\
\end{array}$ & $\begin{array}{l}28.2 \\
18.8 \\
18.8 \\
14.5 \\
28.2 \\
\end{array}$ & $\begin{array}{c}5 \\
1 \\
101 \\
2 \\
115 \\
\end{array}$ & $\begin{array}{c}4.3 \\
0.9 \\
86.3 \\
1.7 \\
98.3 \\
\end{array}$ & $<0.001^{*}$ & $\begin{array}{l}32 \\
19 \\
20 \\
18 \\
32 \\
\end{array}$ & $\begin{array}{l}27.4 \\
16.2 \\
17.1 \\
15.4 \\
27.4 \\
\end{array}$ & $\begin{array}{l}33 \\
20 \\
22 \\
20 \\
34 \\
\end{array}$ & $\begin{array}{l}28.2 \\
17.1 \\
18.8 \\
17.1 \\
29.1 \\
\end{array}$ & $>0.05$ \\
\hline $\begin{array}{l}\text { Waste dispose of pad } \\
\text { Throw it routine waste } \\
\text { Throw on road side /garden } \\
\text { Burn it or landfill } \\
\text { Reply to used after boiling } \\
\text { House dust bin }\end{array}$ & $\begin{array}{l}17 \\
20 \\
21 \\
17 \\
40 \\
\end{array}$ & $\begin{array}{l}14.5 \\
17.1 \\
17.9 \\
14.5 \\
34.2 \\
\end{array}$ & $\begin{array}{c}114 \\
0 \\
1 \\
1 \\
1 \\
\end{array}$ & $\begin{array}{c}97.4 \\
0 \\
0.9 \\
0.9 \\
0.9 \\
\end{array}$ & $<0.001^{*}$ & $\begin{array}{l}20 \\
18 \\
17 \\
33 \\
29 \\
\end{array}$ & $\begin{array}{l}17.1 \\
15.4 \\
14.5 \\
28.2 \\
24.8 \\
\end{array}$ & $\begin{array}{l}21 \\
19 \\
17 \\
31 \\
29 \\
\end{array}$ & $\begin{array}{l}17.9 \\
16.2 \\
14.5 \\
26.5 \\
24.8 \\
\end{array}$ & $>0.05$ \\
\hline $\begin{array}{l}\text { Methods of drying } \\
\text { Expose to the sun } \\
\text { Artificial dry }\end{array}$ & $\begin{array}{l}66 \\
51\end{array}$ & $\begin{array}{l}56.4 \\
43.6\end{array}$ & $\begin{array}{c}116 \\
1\end{array}$ & $\begin{array}{c}99.1 \\
0.9\end{array}$ & $<0.001^{*}$ & $\begin{array}{l}64 \\
53\end{array}$ & $\begin{array}{l}54.7 \\
45.3\end{array}$ & $\begin{array}{l}64 \\
53\end{array}$ & $\begin{array}{l}54.7 \\
45.3\end{array}$ & $>0.05$ \\
\hline
\end{tabular}

$\mathrm{p}$ : $\mathrm{p}$ value for comparing between pre and post program

*: Statistically significant at $\mathrm{p} \leq 0.05$

Figure ( 1 ) Distribution of the study and control groups according to sources of information

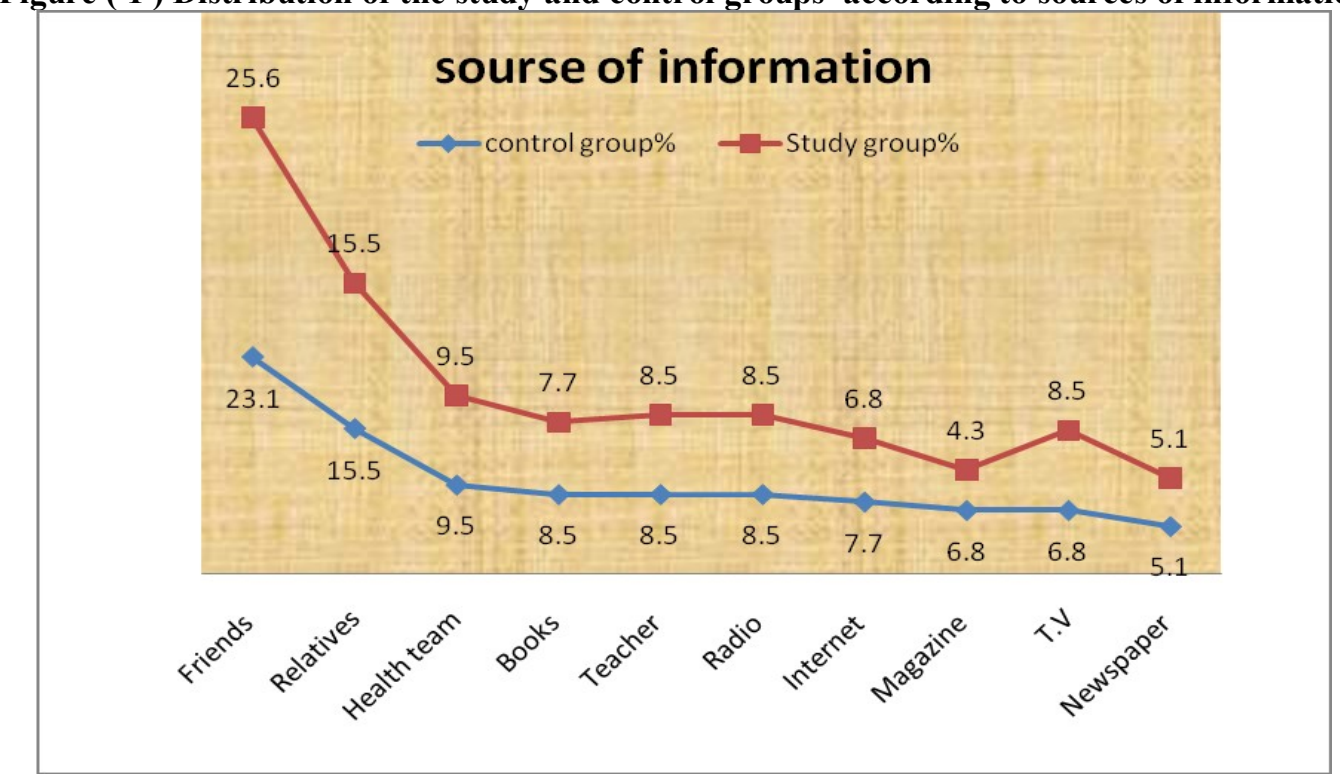

